\title{
Use of biogas to power diesel engines with common rail fuel systems
}

\author{
Stawomir Wierzbicki ${ }^{1, *}$, Michat Śmieja ${ }^{1}$ \\ ${ }^{1}$ University of Warmia and Mazury in Olsztyn, Faculty od Technical Science, 11 Oczapowskiego str, \\ 10-957 Olsztyn, Poland
}

\begin{abstract}
The limited resources of fossil fuels, as well as the search for a reduction in emissions of carbon dioxide and other toxic compounds to the atmosphere have prompted the search for new, alternative energy sources. One of the potential fuels which may be widely used in the future as a fuel is biogas which can be obtained from various types of raw materials. The article presents selected results as regards the effects of the proportion of biogas of various compositions on the course of combustion in a dual-fuel diesel engine with a Common Rail fuel system. The presented study results indicate the possibility for the use of fuels of this type in diesel engines; although changes are necessary in the manner of controlling liquid fuel injection.
\end{abstract}

\section{Introduction}

The ongoing climate change related to, inter alia, global warming and growing public awareness combined with a constant increase in demand for energy have prompted the search for new energy sources. In recent years there has been a strong emphasis on increasing the use of energy obtained from renewable sources. Particular attention is being paid to second generation renewable fuels that are manufactured from non-food products, which means that fuel production does not compete with food production.

One of the fuels of this type is biogas, which is generated spontaneously in nature as a result of natural processes and can also be produced in special biogas plants from various types of biomass $[1,2,3,4,5]$. The produced biogas contains considerable amounts of methane $(40-75 \%)$ which is the main combustible component, and of non-combustible carbon dioxide $(25-55 \%)$ which is a ballast. In addition, depending on the origin, biogas may contain small (at a level of a few per cent) amounts of other components, such as hydrogen, carbon monoxide, nitrogen and oxygen, as well as trace amounts of hydrogen sulphide and other chemical compounds. Given that biogas may be obtained using various production technologies, its chemical composition is not constant. The basic and most desirable biogas component is methane, i.e. the simplest hydrocarbon. The percentage of methane in biogas is determined by the technology of biogas production and ranges from $35 \%$ to approx. $75 \%[1,2,6]$. Table 1 presents the compositions of biogas, including methods of obtaining it.

Table 1. Composition of biogas, depending on its origin $[1,2,6]$.

\begin{tabular}{|l|c|c|c|}
\hline \multirow{2}{*}{ Component } & \multicolumn{3}{|c|}{ Content } \\
\cline { 2 - 4 } & agricultural biogas & treatment plant biogas & landfill biogas \\
\hline Methane $\mathrm{CH}_{4}$ & $45-75 \%$ & $57-62 \%$ & $37-67 \%$ \\
\hline Carbon dioxide $\mathrm{CO}_{2}$ & $25-55 \%$ & $33-38 \%$ & $24-40 \%$ \\
\hline Oxygen $\mathrm{O}_{2}$ & $0,01-2,0-2,1 \%$ & $0-0,5 \%$ & $1-5 \%$ \\
\hline Nitrogen $\mathrm{N}_{2}$ & $0,01-5,0 \%$ & $3,4-8,1 \%$ & $10-25 \%$ \\
\hline
\end{tabular}

*Corresponding author: slawekw@uwm.edu.pl 


\begin{tabular}{|l|l|l|l|}
\hline Hydrogen sulphide $\mathrm{H}_{2} \mathrm{~S}$ & $10-30000 \mathrm{ppm}$ & $24-8000 \mathrm{ppm}$ & $15-427 \mathrm{ppm}$ \\
\hline
\end{tabular}

The major advantage of fuels of this type, e.g. biogas, is primarily the relatively short time of their renewal in nature $[1,2,3]$. Carbon dioxide introduced to the atmosphere as a result of the combustion of these fuels is, most frequently, of plant or animal origin, and, assuming that it will be used by plants in the next vegetation cycle, the process of the use of such a fuel becomes a component of the natural carbon circulation and generally lasts no longer than one year. An example of carbon circulation when using all types of organic wastes for the production of biogas used to generate electricity and heat is presented in Figure 1 [7].

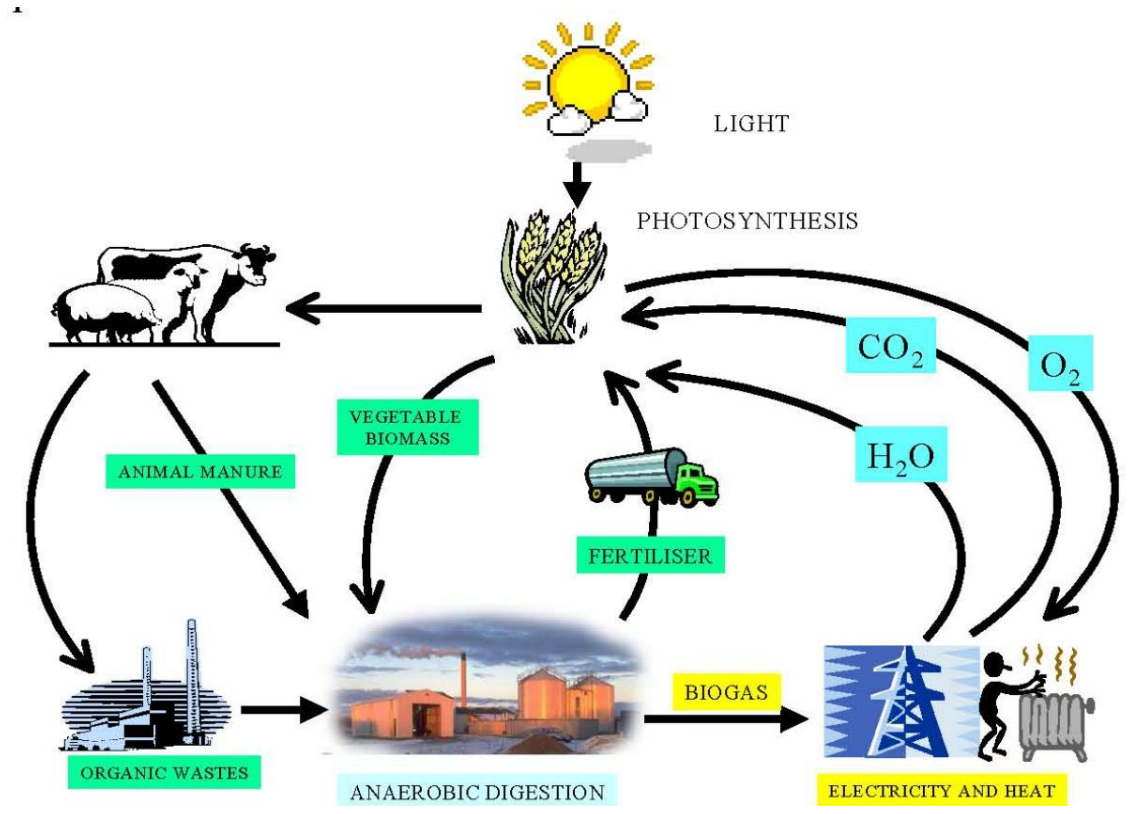

Fig. 1. Natural carbon circulation with biogas used as a fuel in cogeneration systems [7].

It is also worth stressing that the production of biogas is the most efficient form of the conversion of organic raw materials into a fuel. This is due to the fact that the production of liquid fuels such as biodiesel or ethanol use various types of grains, e.g. rape, while the production of biogas uses whole plants. What is most important is that there is a possibility of the production of biogas from wastes, even those generated in the production of liquid fuels. Figure 2 presents, in a diagrammatic form, the amount of energy that is possible to be produced from agricultural crops yielded from an area of 1 ha when converting them into various fuels, with reference to the range of a vehicle with an internal combustion engine consuming 7.41 fuel, or the range of a vehicle with a diesel engine consuming 6.11 fuel [7]. The presented comparison demonstrates that the energy obtained from biogas enables a 3fold increase in the range of a vehicle compared to a vehicle powered by biodiesel or bioethanol obtained from the same area of crops. Therefore, biogas production generates much less waste than liquid fuel production does. 


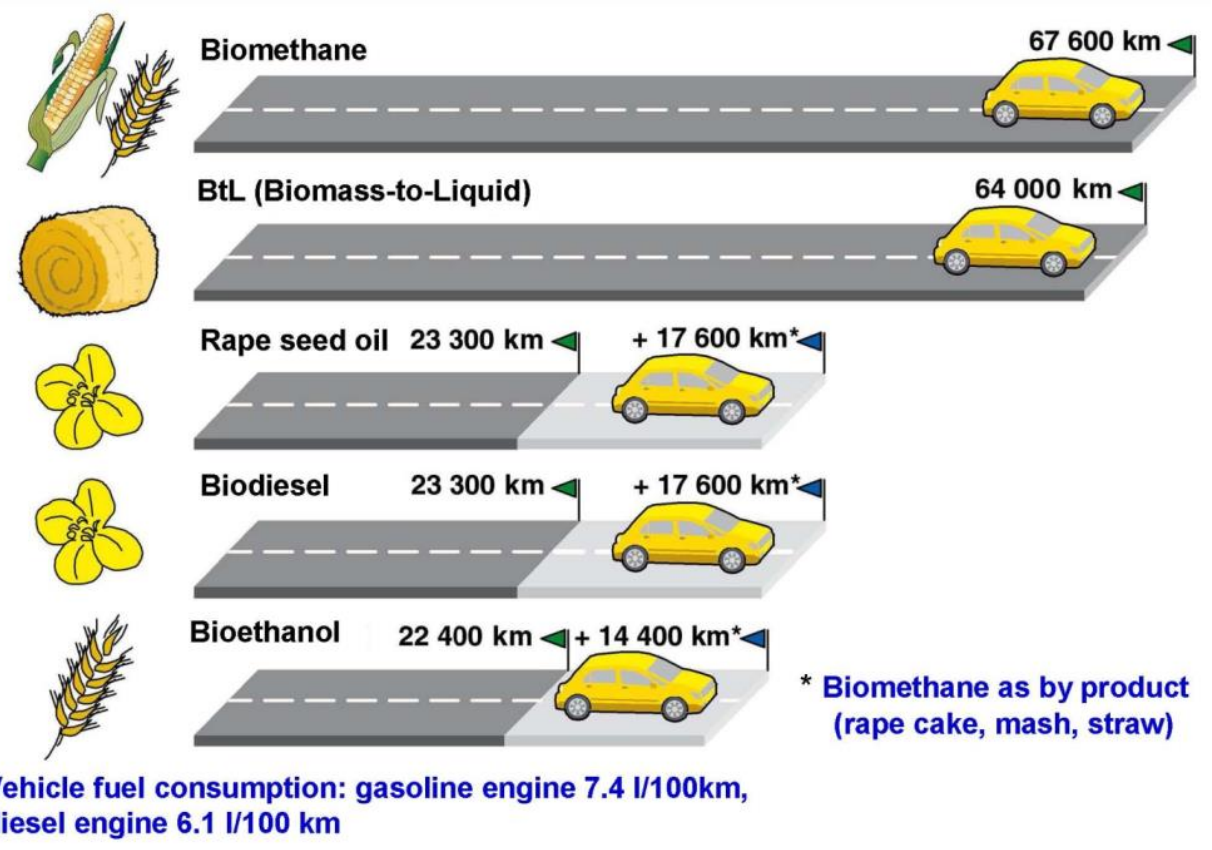

Fig. 2. A comparison of the potential range of a vehicle using different fuels produced from 1 ha of agricultural crops [7]

The properties of biogas as a fuel for internal combustion engines are strictly dependent on the content of particular compounds. They are affected the most by methane, i.e. the basic combustible component of biogas.

Biogas may be used as a fuel for both spark-ignition engines and diesel engines [3, 8 , 10]. The use of biogas to power diesel engines is relatively unexplored and many research centres are currently conducting research into the development of efficient methods of using this fuel. A dual-fuel supply system is required for these engines. This is due to the fact that in order to ignite the air/biogas mixture in the combustion chamber, it is necessary to inject a dose of a liquid fuel whose spontaneous ignition initiates the combustion of a gaseous fuel.

This article presents the results of an analysis of the effect of the proportion of a biogas dose in the supply dose on the course of combustion in a diesel engine with the Common Rail fuel system.

\section{Objective of the research and test bench description}

This paper presents the preliminary test results of a compression ignition engine run in a dual-fuel system, fuelled with gaseous fuel with varying chemical composition.

The tests described were performed on an ADCR engine manufactured by Andoria-Mot. For the engine technical specifications, refer to table 2 [11].

The engine examined was installed in an AVL engine test bed ensuring proper engine load and measurement of basic operating parameters, including the rotational speed, torque and fuel consumption.

Furthermore, as the engine was running, the course of pressure changes in the first cylinder chamber were recorded using the 6056A type probe made by Kistler, placed in the glow plug seat with the aid of a special adapter. The probe was combined with the 5018A load amplifier, which was connected via DAQ card to a PC. The crankshaft rotation angle was measured by an optical sensor installed on the crankshaft. The angle marker resolution 
was 720 points/revolution in this case, which enabled pressure recording every $0.5^{\circ}$ of crankshaft revolution, within the full range of the engine's work cycle [11].

Table 2. Technical data of the ADCR engine [11].

\begin{tabular}{|c|c|}
\hline Engine & ADCR \\
\hline Engine type & $\begin{array}{c}\text { Diesel, 4-cycle, turbocharged } \\
\text { with charge air cooler }\end{array}$ \\
\hline $\begin{array}{c}\text { Number and } \\
\text { arrangement of } \\
\text { cylinders }\end{array}$ & 4 cylinders in-line, vertical \\
\hline $\begin{array}{c}\text { Bore diameter / piston } \\
\text { stroke }\end{array}$ & $94 / 95 \mathrm{~mm}$ \\
\hline Swept volume & $2636 \mathrm{~cm} 3$ \\
\hline Compression ratio & $85 \mathrm{~kW} / 3700 \mathrm{rpm}$ \\
\hline $\begin{array}{c}\text { Rated power*/speed } \\
\text { Peak torque*/speed }\end{array}$ & $250 \mathrm{Nm} / 1800-2200 \mathrm{rpm}$ \\
\hline $\begin{array}{c}\text { Specific fuel } \\
\text { consumption at peak } \\
\text { torque* }\end{array}$ & $210 \mathrm{~g} / \mathrm{kWh}$ \\
\hline Injection system / & Common Rail CR2.0 (Bosch) \\
\hline $\begin{array}{c}\text { Turbocharger } \\
\text { valve }\end{array}$ \\
\hline
\end{tabular}

* in accordance with ISO 1585 / wg normy ISO 1585

Fig. 3. Test bench.

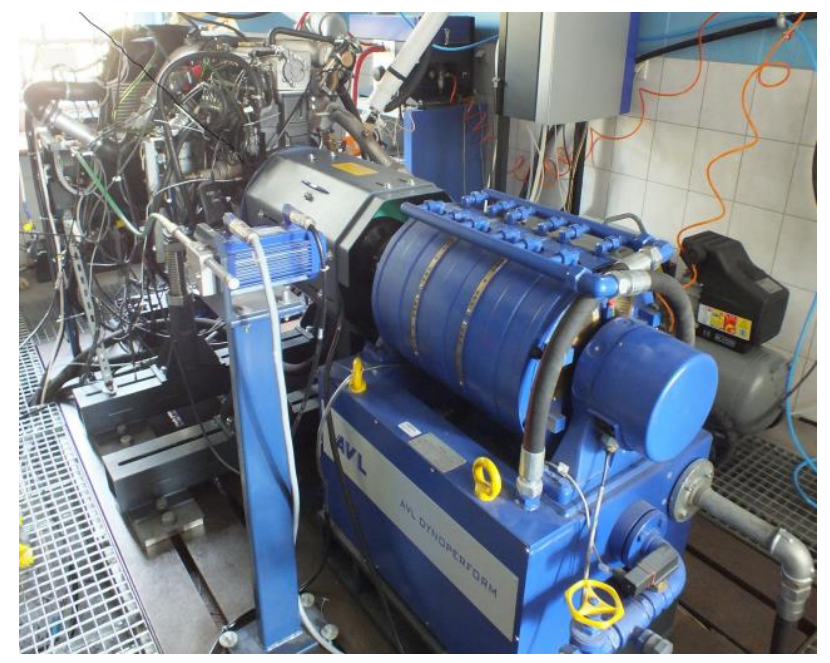

To complete the testing programme planned, a system was developed that enabled fuelling the engine with gaseous fuel with the assumed chemical composition, created artificially in a laboratory $[11,12]$. Based on available literature data, it was assumed that the fuel fed to the engine during the tests will be a mixture of two main components of agricultural biogas, namely methane $\left(\mathrm{CH}_{4}\right)$ and carbon dioxide $\left(\mathrm{CO}_{2}\right)$. The percentage of other chemical compounds present in the biogas derived from agricultural biogas plants is negligible (below 1\%), and thus, they were not considered in the fuel being tested.

Methane-rich natural gas type $\mathrm{E}$ from the municipal gas network, the composition of this class of natural gas is as follows:

- methane $\left(\mathrm{CH}_{4}\right)$ - ca. $97.8 \%$; 
- ethane, propane, butane - ca. $1 \%$;

- nitrogen $\left(\mathrm{N}_{2}\right)$ - ca. $1 \%$;

- carbon dioxide $\left(\mathrm{CO}_{2}\right)$ and other components - $0.2 \%$.

The gas available in the gas network, at the time of the tests, had a caloric value of $36.335-36.374 \mathrm{MJ} / \mathrm{m}^{3}$, as declared by the supplier - the Polish Gas Company (PSG).

As was assumed, in addition to methane as the main combustible component, the gaseous fuel should contain carbon dioxide. Compressed carbon dioxide with a purity class of 2.2 , thus containing $99.2 \% \mathrm{CO}_{2}$, was used in the tests. This is a typical industrial gas commonly used for welding purposes.

To create fuel with the assumed chemical composition, the above gases were fed to the engine inlet manifold through a special system made for the purpose of the project, ensuring the designed flow rate of individual components of the gaseous fuel [13].

Figure 4 shows a general diagram of the system supplying gaseous fuel.

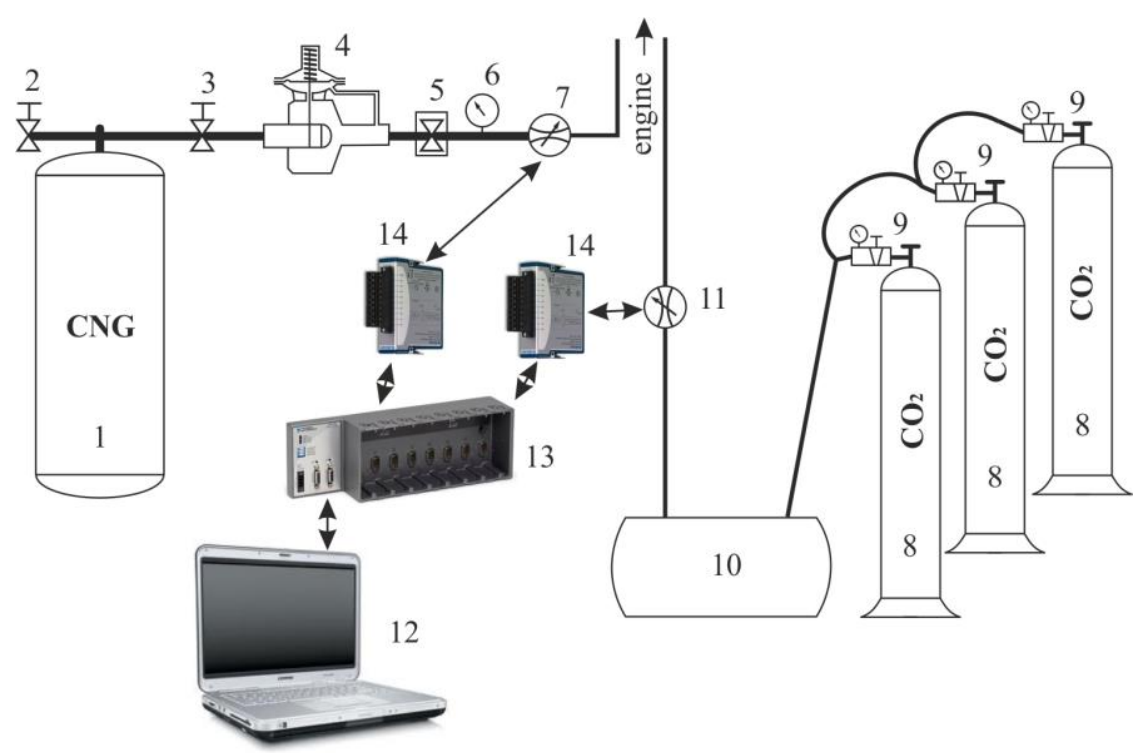

Fig. 4. Block diagram of the gaseous fuel supply system: 1 - CNG cylinder, 2 - filling valve, 3 - cutoff valve, 4 - two-stage reducer, 5 - solenoid valve, 6 - pressure gauge, 7 - MasStream gas mass flow regulator, $8-\mathrm{CO}_{2}$ cylinders, 9 - reducers with pressure gauges, 10 - expansion tank, 11 - mass flow regulator, 12 - PC, 13 - CompactRio programmable controller, 14 - i/o cards to control the flow regulators.

During the study, an ADCR engine was controlled by an original Bosch EDC16C39 device with original engine-controlling software adjusted to single fuel operation. Depending on the current engine operating conditions, e.g. the engine speed or the load, the controlling device follows various control strategies. During the study, the engine controls maintained constant engine load by selecting a fuel dose depending on the engine operating conditions, taking into account the gaseous fuel dose. This resulted, with the increase in the proportion of a gaseous fuel, in a reduction in the liquid fuel dose injected into the combustion chamber.

\section{Test results}

At the first stage of the tests, the gaseous fuel dose was increased until the engine ran steadily without signs of knocking combustion. Table 3 shows selected results of this stage of the tests. 
The energy share of diesel fuel $U_{\mathrm{df}}$ in the total engine fuel dose was determined from the relationship:

where:

$$
U_{o n}=\frac{n \&_{d f} \cdot W_{d f}}{n \&_{d f} \cdot W_{d f}+I_{g}^{\&} \cdot W_{g}} \cdot 100 \%
$$

$n k_{l f}$ - diesel fuel mass stream;

$I_{g}^{\&}$ - stream of CNG supplied to the engine;

$\mathrm{W}_{\mathrm{df}}$ - diesel fuel caloric value;

$\mathrm{W}_{\mathrm{g}}$ - CNG caloric value.

Figure 5 presents diagrams of the pressure course in the engine combustion chamber at $\mathrm{n}=1500 \mathrm{rpm}$ and $\mathrm{T}=100 \mathrm{~N} \cdot \mathrm{m}$ for various gaseous fuel compositions when supplying to the engine a gaseous fuel dose corresponding, in energy terms, to $\mathrm{Ug}=50 \%$ of a liquid fuel dose under conditions of a single fuel supply. Figure 5 presents the pressure courses for the same load conditions and the $75 \%$ energy share of a gaseous fuel in relation to the liquid fuel dose under conditions of a single fuel operation.
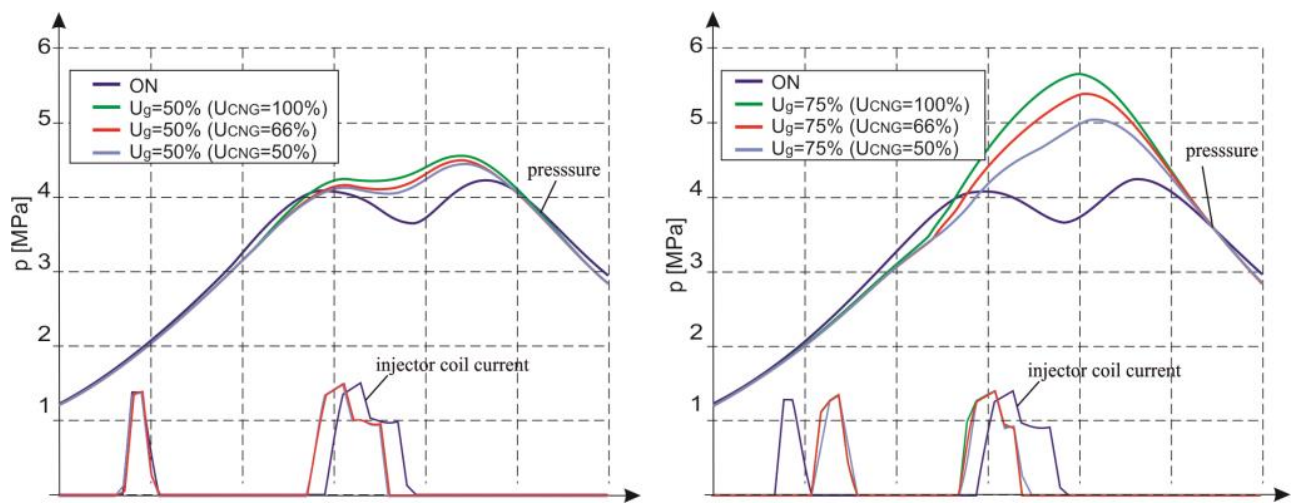

Fig. 5. Pressure change courses in the engine combustion chamber at $n=1500 \mathrm{rpm}, \mathrm{T}=100 \mathrm{~N} \cdot \mathrm{m}$, various compositions of gaseous fuels for gaseous fuel doses corresponding to: a) $50 \%$ dose of a liquid fuel under conditions of single fuel operation, and b) $75 \%$ dose of a liquid fuel under conditions of single fuel operation

As can be seen in fig. 5, supplying a gaseous fuel to the combustion chamber significantly changes the course of combustion, which is associated with the initiation of the combustion of gaseous fuel by the ignition of the pilot dose, which consequently leads to a greater increase in pressure in the initial combustion phase. At the same time, the effects of chemical composition of a gaseous fuel on the course of charge compression in the combustion chamber and on the course of its combustion can be observed. In addition, the courses presented in fig. 5a clearly indicate a significant effect of the gaseous fuel dose volume on the course of combustion. At lower proportions of this fuel, the mixture present in the combustion chamber has a relatively high $\lambda$ value and, as soon as the combustion of a liquid fuel pilot dose stops, the flame goes out and the further combustion of the gaseous fuel only takes place along with the combustion of the liquid fuel main dose. On the other hand, with a richer mixture, the combustion of the gas and air mixture is intensified.

The courses presented in fig. 5 also enable the observation of the effects of the proportion of carbon dioxide in the supply dose on the course of pressure changes in the combustion chamber. As the proportion of $\mathrm{CO}_{2}$ in the supply dose increases, the maximum pressure in the combustion chamber drops, which is associated with an increase in the specific heat of the charge. 
Figure 6 presents the courses of pressure changes in the combustion chamber at $n=3000$ rpm and $\mathrm{T}=100 \mathrm{~N} \cdot \mathrm{m}$ for single fuel operation and for dual fuel operation, at various proportions and compositions of the gaseous fuel. At this engine speed, one dose of fuel is injected into the combustion chamber.
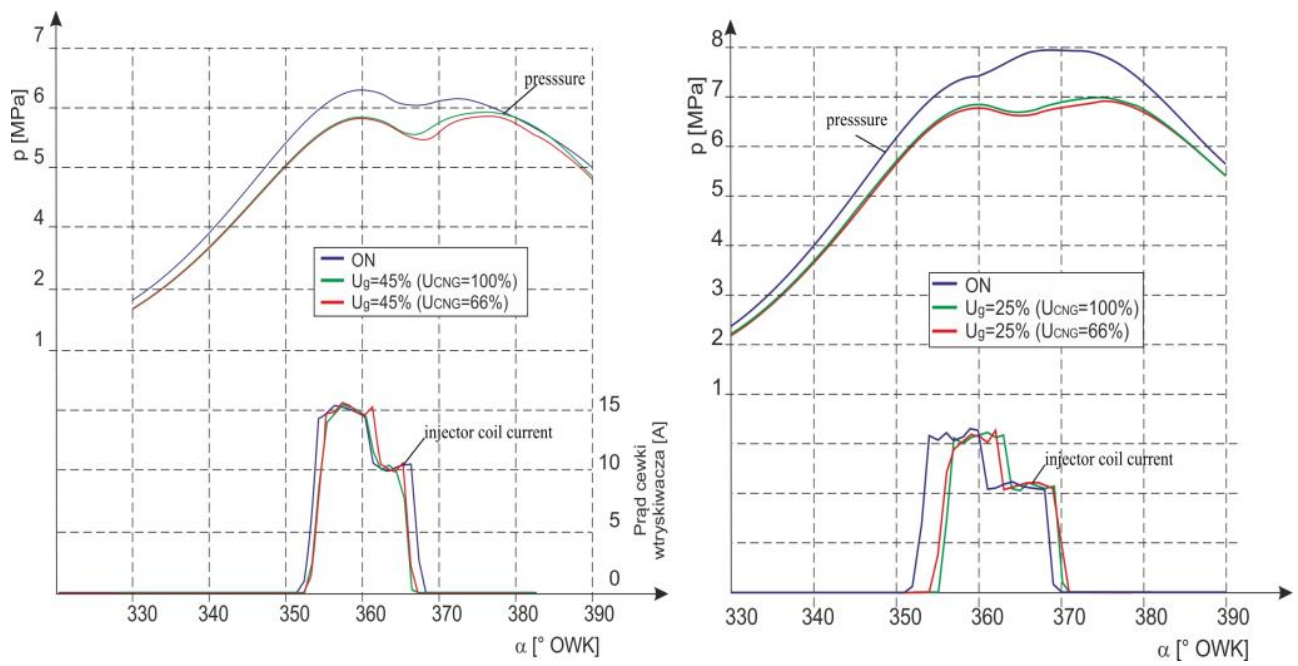

Fig. 5. Pressure change courses in the engine combustion chamber at $n=3000 \mathrm{rpm}, \mathrm{M}=100 \mathrm{~N} \cdot \mathrm{m}$, various compositions of gaseous fuels for gaseous fuel doses corresponding to: a) $45 \%$ dose of a liquid fuel under conditions of single fuel operation, $\mathrm{T}=100 \mathrm{~N} \cdot \mathrm{m}$, and b) $25 \%$ dose of a liquid fuel under conditions of single fuel operation, $\mathrm{T}=200 \mathrm{~N} \cdot \mathrm{m}$

An analysis of the presented courses of pressure changes in the combustion chamber clearly shows the significant effect of the proportion of a gaseous fuel on both the course of combustion and the compression of the mixture. An increase in the proportion of a gaseous fuel in the supply dose results in a reduction in the pressure during the compression due to an increase in the specific heat of the gas and air mixture, which leads to a reduction in charge temperature and contributes to a delay in the spontaneous ignition of the liquid fuel.

\section{Conclusions}

The above-presented examples of the effect of the proportion of biogas in a dose supplied to a diesel engine, and the wider study results presented in [3] enable the formulation of the following conclusions:

- there is a possibility for the efficient use of biogas to power diesel engines;

- the course of gaseous fuel combustion process in dual-fuel diesel engines can be controlled by changing the parameters of liquid fuel dose injection;

- due to the high overall efficiency of the engine within a narrow load range, it is suitable for operation in stationary cogeneration systems in hybrid systems and in agriculture to power agricultural tractors;

On the other hand, major disadvantages of such diesel engine powering include:

- the supply of a gaseous fuel to the engine cylinder during the intake stroke prevents the control of the course of combustion in the engine. The combustion of a gaseous fuel starts at the moment of spontaneous ignition of the first liquid fuel dose, which prevents combustion control;

- at partial loads, the overall efficiency of the engine decreases;

Further research into the use of biogas and other gaseous fuels should be carried out in order to select the parameters of the diesel fuel pilot dose and to investigate the possibilities for the application of gaseous fuel direct injection to enable control of its combustion. 


\section{References}

1. J. Cebula J, ACEE Journal, 2, 95-103 (2009)

2. S. Wierzbicki, Journal of Kones 19, 3, 477-482 (2012)

3. D. Barik, S. Murugan, Energy, 72, 760-771 (2014).

4. B. J. Bora, U. K. Saha, Renewable Energy, 87, 782-790 (2016).

5. S. Wierzbicki, Studium możliwości wykorzystania biogazu do zasilania silników o zapłonie samoczynnym (UWM Olsztyn, 2016)

6. http://lemvigbiogas.com/

7. J. Skorek, J. Kalina, Gazowe układy kogeneracyjne. (WNT Warszawa, 2005)

8. M. Mikulski, S. Wierzbicki, M. Śmieja, J. Matijošius, Transport, 30 2, 162-171 (2015)

9. M. Mikulski, S. Wierzbicki, A. Piętak, Eksploatacja i Niezawodność - Maintenance and Reliability, 17, 1, 42-48 (2015)

10. S. Wierzbicki, M. Śmieja, Solid State Phenomena, 210, 136-141 (2014)

11. D. Szpica, Flow measurement and instrumentation, 59, 147-156 (2018)

12. D. Szpica, Transport, 33(1), 186-196 (2018)

13. S. Wierzbicki, M. Mikulski, M. Śmieja, Combustion Engines, 162(2), 91-101 (2015) 